\title{
Prevalence of Dental Anxiety Among Patients Visiting Dental Institution- A Cross Sectional Study
}

\author{
1. Dr. Srividhya.S Mds \\ Associate Professor \\ Department of Oral Medicine and Radiology \\ Faculty of Medicine \\ Meenakshi Academy of Higher Education and Research \\ Chennai, India
}

\begin{abstract}
:-
\section{$>$ Aim and Objective:}

Anxiety exhibited by patients towards dental procedures are common problems experienced by many across the world. This study focuses on evaluating the dental anxiety among patients attending the outpatient clinics of Meenakshi Ammal Dental College and Hospital and its association with their age, gender, educational level.
\end{abstract}

\section{> Methodology:}

A total of 200 patients, aged 21-50 years were included in the study. A questionnaire comprising the Corah's Dental Anxiety Scale was used to assess the level of dental anxiety. The data obtained was analyzed using SPSS software.

\section{$>$ Results:}

Independent $t$-test did not show significant variation among the age groups with respect to overall anxiety score $(P \geq 0.05)$, however, it was reduced with increasing age. There was no significant difference was found by independent $t$-test between male and female groups and regarding previous dental visit $(P \geq 0.05)$. Regarding education level, there was no statistical difference between the groups $(P>0.05)$.

\section{Conclusion:}

Younger patients, female patients were associated with increased anxiety scores.

\section{Clinical Significance:}

The present study was done for better patient management and proper treatment plan development for dentally anxious patients.

Keywords:- Dental Anxiety, Dental Treatment, Modified Dental Anxiety Scale.

\author{
2. Dr. Saraswathi Gopal Mds \\ Professor and Head \\ Department of Oral Medicine and Radiology \\ Faculty of Medicine \\ Meenakshi Academy of Higher Education and Research \\ Chennai, India
}

\section{INTRODUCTION}

Anxiety is often expressed as an unpleasant feeling and imaginary percerption accompanied by the premonition that something undesirable is going to happen. It is defined as apprehension of danger, often accompanied by restlessness, tension, tachycardia, and dyspnea which may not be attributed by a definable cause.[1]It can also be described as an individual's reaction to a perceived danger which is characterized by feelings of tension, worry, apprehension often involving physical changes such as increased blood pressure, nausea, and palpitation. Fear is a biological response and a reaction to a known danger or threat. $[2,3]$ The terminologies such as anxiety, phobia, and fear are often used interchangeably in the literature.

Even though there are many advancements in terms of dental technology, restorative materials, and increased oral health awareness, many people are anxious for dental procedures. Dental anxiety ranks fourth among common fears [4]The dental anxiety could be attributed to factors such as personality characteristics, past traumatic dental experience in childhood by self or learning from dentally anxious family members or friends, fear of pain .[5]Dental anxiety socioeconomic status. Identification of such dentally anxious patientsis critical for better management and treatment outcome.

Individuals who are anxious usually have poorer dental health, more missing and decayed teeth when compared to non-anxious patients because they avoid dental treatment and delay their dental visit.[6] People who constantly delay their dental visit for a prolonged time, even if they are experiencing pain, they end up having extensive problems requiring more complex treatment. Also, their poor oral health status can affect their quality of life .[7]

Anxious patients require more analgesics for pain relief.[8] Dental anxiety has a profound impact on pain through their entire time period of treatment, and therefore, it should be identified as an significant step not only in the management of anxiety for patients with high-dental anxiety but also in pain control for all patients. 
There have been several scales developed to assess patients' anxiety and fear level so that proper management strategies can be employed. Dental anxiety can be assessed using many anxiety questionnaires such as Dental Fear Survey (DFS), Corah's Dental Anxiety Scale (CDAS), Modified Dental Anxiety Scale (MDAS[9,10]

CDAS is the most popular scale for measuring dental anxiety. This scale is very reliable and valid. Answering the questionnaire is easy and quick, hence it is appropriate for clinical use. It is a brief seven item questionnaire. Each item has five answers; the answers vary from "non anxious" scored 1 to "extremely anxious" scored 5 . The scale is straight-forward and easy to complete and time needed for finishing is also less.[11] making the patients to fill the questionnaire does not in crease their anxiety.

Few studies are available on the prevalence of dental anxiety and factors affect ingtheir anxiety. The present study was conducted in an attempt to develop better management and treatment strategies for patients who are anxious for dental procedures.

\section{METHODOLOGY}

\section{Material and Methods}

This study design is cross-sectional and was conducted for 15 days among patients attending the outpatient clinics of an institution in Chennai. The study was conducted in June 2018 among 200 patients (aged 21-50 years) attending the out patient clinics of Meenakshi Ammal dental College and hospital, Chennai. Patients who had generalized anxiety disorders and intellectual disability were excluded. Informed consent was obtained from all patients after explaining the study and questionnaire were given to them and collected back.

Patients were categorized into three groups according to their age - Group I: 20-39 years and Group II - 30$39 y e a r s$ and Group III $-40-50$ years.

Questionnaire consisted of a basic details regarding age, gender, educational level and a questionnaire comprising a set of 7 questions (which included the Corah's Dental Anxiety Scale) were distributed among patients visiting our out patient clinic.

CDAS consists of 7 questions; It concerns patients' anxiety in the following situations:

In a score of 5 rate your anxiety level for the respective questions
1. Expecting a visit to dentist

2. Waiting for an appointment and treatment in the dentist's office

$>$ 3.Waiting for teeth cavity drilling procedure on the dental chair

$>$ 4. Waiting for cleaning the teeth on the dental chair

$>$ 5.Waiting for an administration local anesthetic injection on the dental chair

6. Expense for the treatment

7. Final outcome of the treatment

Rating Scores

- 1- not anxious,

- 2-mildly anxious

- 3- building Tension

- 4- very Anxious

- 5-extremely anxious with sweating

Summation of each and every answer with a score for the level of anxiety with a minimum score of 7 and a maximum score of 35 . Patients with anxiety scores of 14 or more are considered mild anxious for dental procedure. Anxiety scores from 15-24 are considered to indicate moderate anxiety; and scores from 25-35 are considered to indicate high anxiety. Data was analyzed using SPSS Statistics for Windows. The independent t-test was used to study the difference between the groups.

\section{RESULTS}

Out of the 200 patients, who participated in the study, 120 were females and 80 were males. The selected patients were allocated to three age groups $-53 \%$ of them belong to the age group $20-29 ; 22 \%$ of them belong to the age group $30-39$; and $24 \%$ belong to $40-50$ years.68\% of them completed secondary education and the remaining $32 \%$ finished their primary education.

The incidence of anxiety for dental procedure among the study population was $70 \%$. Based on the grading of dental anxiety, $62 \%$ of patients were found to be moderately anxious, $8 \%$ of patients were found to be highly anxious for dental procedure and treatment. $30 \%$ of patients were found to be mild anxious.

Table 1 and graph 1 depicts the correlation of grades of anxiety among different age groups. Among three age groups, majority were moderately anxious and anxiety was decreased in the old age group. Independent t-test did not show a statistically significant difference between the mean total score among three age group $(\mathrm{P}>0.05)$.

\begin{tabular}{|c|c|c|c|}
\hline Age groups & Grade 1(mild anxious) & $\begin{array}{c}\text { Grade2 (moderately } \\
\text { anxious) }\end{array}$ & Grade 3(highly anxious) \\
\hline Group 1 & 26 & 70 & 10 \\
\hline Group2 & 12 & 30 & 2 \\
\hline Group 3 & 22 & 24 & 4 \\
\hline
\end{tabular}

Table 1:- showing age groups and grades of anxiety 
ISSN No:-2456-2165

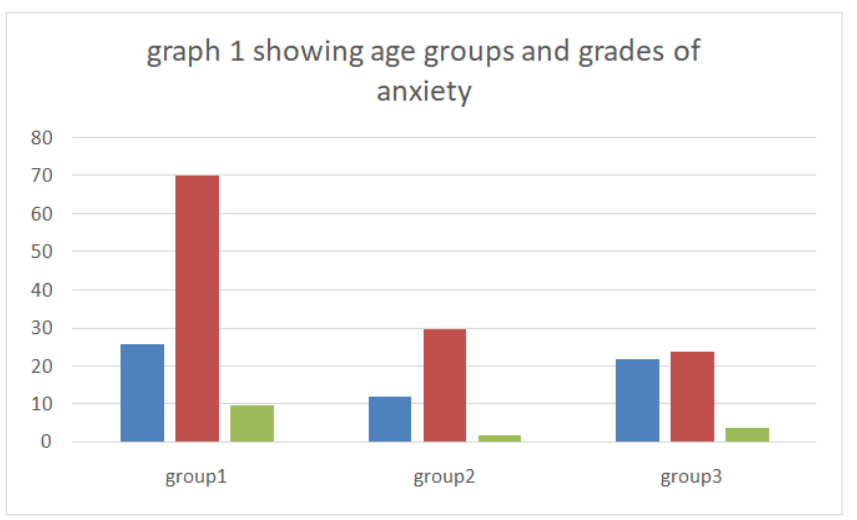

Most of the women selected in the study were "more anxious" toward all items in the dental anxiety questionnaire. But Independent t-test did not show a statistically significant difference between the mean total score of the two gender group $(\mathrm{P}>0.05)$.

\begin{tabular}{|c|c|c|c|}
\hline Gender & Grade 1 & Grade2 & Grade 3 \\
\hline Males & 32 & 44 & 4 \\
\hline Females & 28 & 80 & 12 \\
\hline
\end{tabular}

Table 2:- showing gender and grades of anxiety

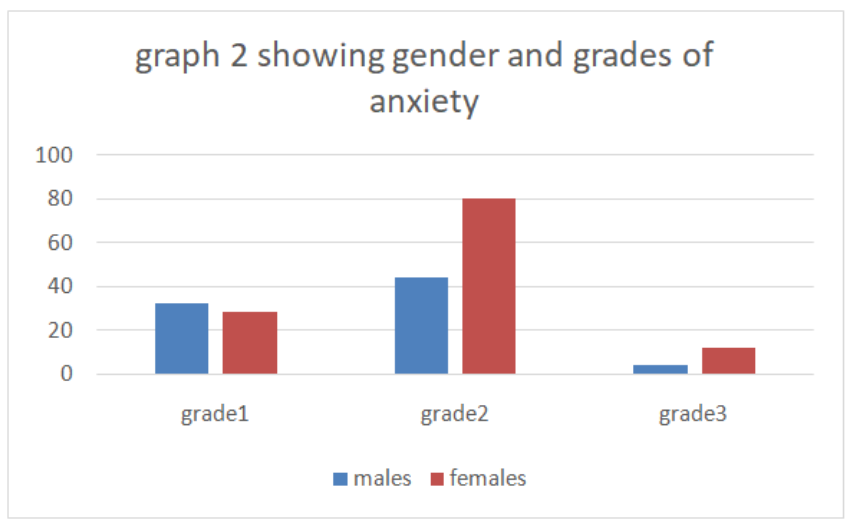

Regarding the education level, the independent t-test demonstrated no significant difference between the mean dental anxiety score of the two groups [Table 3]. But educated people and females seemed to have higher levels of anxiety with regard to cost and outcome of the treatment according to our study

\begin{tabular}{|c|c|c|c|}
\hline Level Of Education & Grade1 & Grade2 & Grade3 \\
\hline secondary & 38 & 88 & 10 \\
\hline primary & 22 & 36 & 6 \\
\hline
\end{tabular}

Table 3:- showing level of education and grades of anxiety

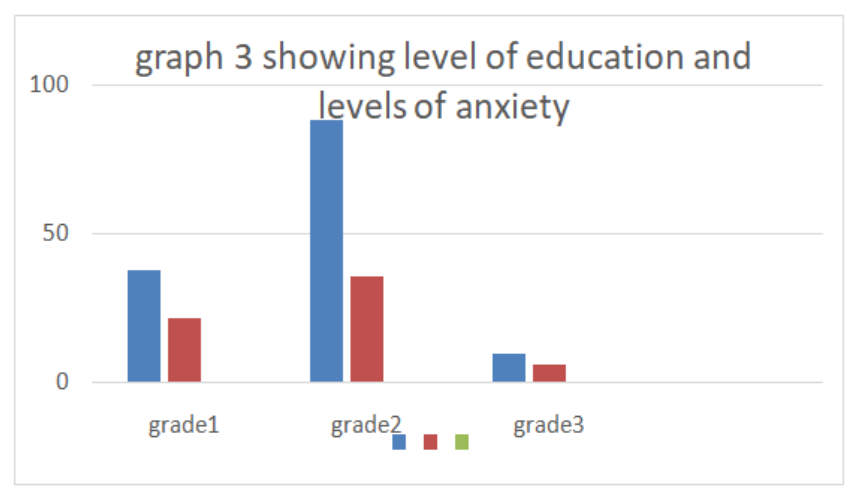

\section{DISCUSSION}

The present study was carried out to assess the anxiety level among the patients for dental procedures and the factors affecting anxiety among them attending the outpatient clinics of a private institution in Chennai. The prevalence of anxiety between the study population was $70 \%$.Based on the grading of dental anxiety, $31 \%, 60 \%$, and $9 \%$ of the patients were found to be non anxious, moderately anxious, and highly anxious, respectively.

The findings from this study showed no significant difference between the age and dental anxiety score. This is in accordance to the findings of Tunc (2005) and Saatchi (2015) who reported that the fear and anxiety were not influenced by age. $(12,13)$

The results from our study showed no significant difference between the gender and dental anxiety. This is not in accordance with the studies by Erten (2006) Auerbach, (1978) Saatchi, (2015) . our results is in accordance with the study by Thomson et al. (2000) .This result may be attributed to cultural differences.[14,13,15,16]

Regarding education, the results of the present study showed that educational background had no significant effect on anxiety toward dental procedures. There was no statistical significant difference in the dental anxiety between educated and non-educated group. This result is in accordance with the study by Saatchi[13] who mentioned that the anxiety towards dental procedures was not affected by education level. The result is not in accordance with the study by Erten[14] who mentioned that patients with a primary school education had the highest anxiety scores in comparison to highly educated patients.

But educated people and females seemed to have higher levels of anxiety with regard to cost and outcome of the treatment according to our study. 


\section{LIMITATIONS}

The limitations of the study could be a smaller sample size, conducting a similar study with larger samples may have improved outcome. There may be chances of bias in the result outcome when such questionnaire study as the patients might over or underestimate their responses. The study samples selected were not of equal distribution.

\section{CONCLUSION}

Although there is no significant statistical difference obtained, it may be drawn into conclusion that young patients and females were dentally more anxious. There is no significant difference in dental anxiety level with regard to the educational status, nevertheless educated people and females seemed to have higher levels of anxiety with regard to cost and outcome of the treatment according to our study.

\section{RECOMMENDATIONS}

Further evaluation and analysis of anxiety associated with dental treatment would help us in better patient management. The treatment can be planned accordingly for patients who are very anxious.

\section{REFERENCES}

[1]. Sinan AY, Deniz O, Mustafa O, Serkan P. An assessment of dental anxiety in oral surgery patients. Gurhane Tip Dergisi2002;44:395-8.

[2]. Rubin JG, Slovin M, Krochak M. The psychodynamics of dental anxiety and dental phobia. Dent Clin North Am 1988;32:647-56.

[3]. Chadwick BL. Assessing the anxious patient. Dent Update 2002;29:448-54.

[4]. Kvale G, Berg E, Raadal M. The ability of Corah's dental anxiety scale and Spielberger state anxiety inventory to distinguish between fearful and regular Norwegian dental patients. Acta OdontolScand1998;56:105-9.

[5]. Seeman K, Molin C. Psychopathology, feelings of confinement and helplessness in the dental chair, and relationship to the dentist in patients with disproportionate dental anxiety (DDA). Acta PsychiatrScand1976;54:81-91

[6]. Armfield JM, Slade GD, Spencer AJ. Dental fear and adult oral health in Australia. Community Dent Oral Epidemiol2009;37:220-30.

[7]. Lin CS, Wu SY, Yi CA. Association between Anxiety and Pain in Dental Treatment. J Dent Res 2017;96:153-62.

[8]. Kazancioglu HO, Dahhan AS, Acar AH. How could multimedia information about dental implant surgery effects patients' anxiety level? Med Oral Patol Oral Cir Bucal 2017;22:e102-e7.

[9]. Al-Namankany A, Ashley P, Petrie A. The development of a dental anxiety scale with a cognitive component for children and adolescents. Pediatr Dent 2012;34:e219-24.
[10]. Klages U, Einhaus T, Seeberger Y, Wehrbein H. Development of a measure of childhood information learning experiences related to dental anxiety. Community Dent Health 2010;27:122-8.

[11]. Coolidge T, Arapostathis KN, Emmanouil D, Dabarakis N, Patrikiou A, Economides N, et al. Psychometric properties of Greek versions of the Modified Corah Dental Anxiety Scale (MDAS) and the Dental Fear Survey (DFS). BMC Oral Health 2008;8:29.

[12]. Tunc EP, Firat D, Onur OD, Sar V. Reliability and validity of the Modified Dental Anxiety Scale (MDAS) in a Turkish population. Community Dent Oral Epidemiol2005;33:357-62.

[13]. Saatchi M, Abtahi M, Mohammadi G, Mirdamadi M, Binandeh ES. The prevalence of dental anxiety and fear in patients referred to Isfahan Dental School, Iran. Dent Res J (Isfahan) 2015;12:248-53.

[14]. Erten H, Akarslan ZZ, Bodrumlu E. Dental fear and anxiety levels of patients attending a dental clinic. Quintessence Int 2006;37:304-10

[15]. Auerbach SM, Kendall PC. Sex differences in anxiety response and adjustment to dental surgery: Effects of general vs. specific preoperative information. J Clin Psychol1978;34:309-13.

[16]. Thomson WM, Locker D, Poulton R. Incidence of dental anxiety in young adults in relation to dental treatment experience. Community Dent Oral Epidemiol2000;28:289-94 